\title{
Pilot research on a pupil's psychological safety in the multicultural educational environment
}

\author{
Tatyana I. Kulikova \\ Department of Psychology and Pedagogy, Tula State Lev Tolstoy Pedagogical University, \\ Tula, Russia
}

Corresponding author. E-mail: tativkul@gmail.com

\begin{abstract}
In the modern world, the environment of any educational institution represents a spectrum of ethnic groups and subcultures: a multicultural educational environment. Pupils who are aware of their national identity often demonstrate intolerance toward students of other nationalities, which threatens pupils' psychological safety. In this article, we present the results of pilot research examining the level of a pupil's psychological safety in the multicultural educational environment and identifying the criteria that influence a pupil's psychological safety. The research sample comprised 127 pupils aged 13-14 years from different schools living in various places that differed by the type of settlement, industrial development and level of science and culture. We isolated the following criteria for a pupil's psychological safety in the multicultural educational environment: satisfaction with the educational environment, protection from psychological abuse and self-confidence. According to pupils, the essential characteristics of safety in the educational environment, regardless of school category and type, are being able to ask for help, protection of personal dignity, interactions with other students, and self-respect.

Empirical data reveal the current status of the psychological safety of the entire sample group $(n=127)$ and compare indices of psychological safety in the educational institutions under study.

Analysis of the results of our research indicates that protecting a pupil's personality in the multicultural educational environment has the greatest influence on his/her psychological safety. In addition, a comfortable psychological atmosphere, mutual aid and support of pupils and low levels of classmates' and coevals' aggression positively influence the protection experience.
\end{abstract}

Key words: multicultural education, educational environment, psychological safety

\section{Introduction}

The problem of multicultural education in modern Russia has become more significant during the last decade with the increase in forced migration, refugees and labor migrants. Development of multicultural education is a current issue for "most 
Russian territorial units - republics, territories and regions, for cities and towns and rural settlements. The problem of the multicultural approach is also relevant for Tula Region. According to Regional Statistics Service data, migration in Tula Region has been positive in nature since 2005" (Kulikova, 2015, p. 831). Since 2014, the flow of refugees from Ukraine has increased. Tula Region has welcomed more than five thousand newly arrived immigrants who were given accommodations and work in the regional center, and their children have been able to study in Tula schools. Certainly, representatives of different nationalities, other cultures and other traditions were among the refugees' children.

Despite the reason, forced migration always leads to changes in the normal pattern of life and the social status of families, the appearance and demonstration of school socialization among refugees' children, and tension among nationalities in the group of coevals. All of these changes are accompanied by emotional experiences and mental disturbance. One of the primary conditions of good health and children's psychological well-being is their experience with psychological safety.

Feeling safe enhances a pupil's mental health, which allows students to assimilate material well and develops his/her mental and psychological characteristics and properties according to that pupil's personal characteristics. Feeling safe enhances appropriate attitudes toward problems and difficulties, eliminates the fear of independence and contributes to a child's physical and mental health. A child who fears school, a teacher or classmates, who is not protected from psychological abuse, is not able to study well and develop normally.

The problem of psychological safety in the educational environment and as a component of the educational process has been actively developing in Russian psychology. Psychological safety in the educational environment has developed theoretically and in application because of the works of V.V. Rubtsov, I.A. Baeva, E.N. Volkova, A.M. Konstantinov, V.A. Yasvin and others. These researchers have shown that an important factor in developing character in the educational environment is safety. Criteria of psychological safety in schools have been developed, and levels of protection of schoolchildren from threats and abuse have been described. Despite these advances, we have not established a sufficient and exact understanding of a pupil's psychological safety in the context of multicultural education.

Ideas regarding the necessity of a child's personality development in a multicultural environment are presented in the pedagogical works of Jan Amos Komensky, J. Pestalozzi, P.F. Kapterev, V.A. Sukhomlinsky, K.D. Ushinsky and others. For example, Komensky created a project of social and cultural changes and the built-in school model. In school programs, special attention is paid to the importance of developing the ability to respond to mutual responsibilities, the skill to live in peace with others and to respect and love those people close to children (Bessarabova, 2007). P.F. Kapterev emphasized that we should apply "not to a single nation but to many" in identifying and enlarging the "drawbacks of your own national ideal... with others' valuable features” (Kolobova, 2005, pp. 105-114). K.D. Ushinsky's concept of a child's personality is based on the principle of integrity, which suggests not only a system of knowledge but also generates moral values, a deep understanding of the meaning of life, relationships between people, realizing one's own place, and the desire and ability to bring harmony and love to the world (Shevchuk, 2001). 
We also observe the issue of the multicultural educational environment in the works of foreign researchers (J. Banks, C. Grant, S. Nieto). According to J. Banks (1996), the process of multicultural education is reflected in five primary functions of a teacher: "integration of contents, the process of knowledge construction, overcoming prejudices, fair pedagogy, development of school culture and social structure" (p. 188). K. Grant (2008) presented the history, the origin and stages of the transformation of multicultural education in the USA.

S. Nieto (2004) observed that the educational environment includes a collection of conditions in which we can see human formation, development and education; and the multicultural environment also provides mutual cultural enrichment in all subjects of the educational process.

In studies on the educational environment, Western researchers accentuate studying the school climate (R. Moos, H. Fend, U. Bronfenbrenner), and the topic of social relations dominates these studies. According to Moos (1979), the construct of "social climate" includes the environment that is subjectively experienced by an individual in certain behavior patterns. The importance of studying schools and the class climate as a subjective component of the educational environment was also emphasized by Fend (1977); in his opinion, an individual "can resist bad material circumstances much easier than human environment, which humiliates or suppresses him" (pp. 9-32). Bronfenbrenner (1979) also believed that psychological components of the environment manage an individual's behavior to a greater extent than "objective" (physical) environmental properties.

Foreign psychologists have conducted studies on the psychological comprehension of safety problems: creating schools that are safe for pupils' emotional health, reforming secondary school to increase school safety, and school abuse research (Bluestein, 2001; Brand, 2003).

Summarizing the research of Western scientists, we can conclude that despite the variety of approaches, most authors focus on the relationship between teachers and students and relationships among students as components of the educational environment that influence the psychological climate.

Traditionally, Russian psychology examined a personality in its interconnection with the social environment. LS. Vygotsky's ideas (1984) were significant in substantiating this thesis. That scientist justly noted that the primary drawback to such research is to study the environment with the help of its absolute indices without reference to a child, and Vygotsky noted that the environment that is identical in terms of absolute indices is completely different for children of different ages. As a unit of environmental study, L.S. Vygotsky cited experience as a unity of the personality and the environment, represented in its development as the "inner attitude of a child as a person to this or that moment of reality" as an indicator of the influence of a particular moment of reality on a child's development. L.S. Vygotsky mentioned that "the environment determines a child's development through environment experience" and appealed for study of the environment to be transferred "to a greater extent inside the child" (pp. 31-32) instead of the external conditions of his/her life.

According to S.L. Rubinstein (2003/1957), a human's entire course of life is defined by the system of his/her basic life relations: to himself/herself, another person and the world as a whole. A person begins his interaction with the [multicultural] 
world, first, as part of the world, and then as one who perceives being able to transform that world.

The outstanding Soviet psychologist A.N. Leontiev (1998/1973), addressing the problem of social and mental conditionality, noted that during the process of his individual development, a person inevitably enters into "special, specific relationships with the surrounding world of things and phenomena which are created by former generations of people" (pp. 108-119). A person's circle of first-hand contacts is "the nearest social environment" or "a social group" that influences the individual in various manners.

According to V.A. Yasvin (2001), the quality of the educational environment is defined by its ability to satisfy the primary needs of the age, for example, needs for safety, recognition, acceptance, respect, social approval, love, and preserving and bolstering self-esteem. N.I. Polivanova and I.V. Ermakova (2000) noted that the educational environment is realized in the teacher's and children's academic work and in their interactions during a lesson or between lessons; they also noted that the educational environment is an important factor in pupils' effective mental development.

\section{Method}

Realizing that the quality of the educational environment in a modern school does not always contribute to children's psychological safety, we conducted pilot research to define the level of a pupil's psychological safety in the multicultural educational environment and to reveal the criteria that influence a student's psychological safety. The sample comprised 127 pupils from $7^{\text {th }}$ and $8^{\text {th }}$ forms, aged 13-14 years, from different schools. The students also lived in places that varied in the type of settlement, degree of development of industrial production and condition of science and culture. We chose Tula (a regional center), Shchyokino (a district center) and the village of Anishino, Venyov District, Tula Region, as the environments. To present the results in a more convenient manner, we labeled the schools (subsamples) that participated in the experiment in the following manner: "1M" (Tula Municipal School), “2D” (Shchyokino District School) and "3R" (Venyov District Rural School). All of the schools that participated in the experiment were multicultural and multinational. The pupils of non-indigenous nationality in these schools numbered $35 \%-65 \%$. All of the pupils lived with their families in the areas in which the schools were situated, and the parents were Russian citizens. The highest percentage of refugee children was in the Venyov District Rural School (subsample "3R").

The homogeneity of the experimental groups was defined using Student's $t$-test. The received empirical value $t=0.3$ was in the insignificance zone $(p \leq 0.05 ; p \leq 0.01)$; therefore, there are no grounds to state the heterogeneity of independent samples. The statistical significance of differences in the experimental distribution was one and the same feature was defined according to $\chi 2-$ Pearson test $(\mathrm{p} \leq 0.05 ; \mathrm{p} \leq 0.01)$. Mathematical data treatment was conducted on the basis of the modern statistical analysis package Statistica 6. Obtained empirical data revealed the current status of psychological safety of the entire sample group $(n=127)$ and compared indices of psychological safety in the educational institutions under study. 
Based on the analysis of research on a person's psychological safety (I.A. Baeva, E.N. Volkova, E.B. Laktionova, 2009), we singled out the following primary criteria of a pupil's psychological safety in the multicultural educational environment:

1) Satisfaction is displayed in experiences of subjective well-being, emotionally positive attitudes from teachers and classmates, satisfaction with one's own academic activity and corresponding behavioral manifestations.

2) Protection is displayed in experiences of support from teachers, support from parents and affection from classmates in addition to the absence of aggressive behavioral manifestations.

3) Self-confidence is displayed in the peculiarities of school anxiety and selfconfidence in difficult situations of learning activities and communication in addition to accepting one's own ethnic identity.

To study the chosen criteria of a pupil's psychological safety, we used a specially designed system of diagnostic methods (Table 1).

Table 1. System of psychodiagnostic methods

\begin{tabular}{ll}
\hline \multicolumn{1}{c}{ Criterion } & \multicolumn{1}{c}{ Methods } \\
\hline Satisfaction & $\begin{array}{l}\text { 1. The questionnaire "Psychological Safety of the Educational Environ- } \\
\text { ment" by I.A. Baeva }\end{array}$ \\
2. Evaluation methods of class atmosphere attractiveness by A.A. Rean \\
Protection & $\begin{array}{l}\text { 1. The questionnaire "Psychological Safety of the Educational Environ- } \\
\text { ment" by I.A. Baeva }\end{array}$ \\
Self-confidence & $\begin{array}{l}\text { 2. Multifactorial scale of coevals' victimization by I.A. Furmanov } \\
\text { 2. Methods of diagnostics of school anxiety level by Fillips } \\
\text { S.V. Ryzhova) }\end{array}$ \\
\hline
\end{tabular}

The questionnaire "Psychological Safety of the Educational Environment" by I.A. Baeva comprises three parts: 1) attitude toward the school educational environment, 2) significant characteristics of the school educational environment and satisfaction with those characteristics, and 3) protection from psychological abuse during interaction. Therefore, the results of this questionnaire indicate the criteria of pupils' attitudes toward the school's educational environment and define the levels of satisfaction and protection as components of the psychological safety of the educational environment (I.A. Baeva, E.N. Volkova, E.B. Laktionova, 2009).

Evaluation methods of class team attractiveness by A.A. Rean define the level of psychological well-being and comfort and in conjunction with other methods, present a more comprehensive picture of a pupil's psychological safety in the educational environment.

The multifactorial scale of coevals' victimization by I.A. Furmanov measures the level of aggression and suggests acquiring information regarding the frequency of direct forms of physical, verbal and social aggression.

Methods of diagnosing school anxiety level by Fillips show the level of a pupil's confidence in various situations of learning activity and communication. In 
our research, we defined the following significant factors that characterize a pupil's psychological safety: common school anxiety, experiences of social stress and fear of self-expression.

Methods of evaluation of ethnic identity types (G.U. Soldatova, S.V. Ryzhova) enable the diagnosis of ethnic self-awareness and its transformation under the conditions of interethnic intensity. We focused particularly on two factors: ethnoegoism and ethno-isolationism.

These methods identify experiences of psychological support from teachers and classmates (protection), experiences of positive emotional attitudes from teachers and classmates (satisfaction), and experiences of school anxiety and acceptance of one's own ethnic identity (confidence).

\section{Results}

The experimental data according to the questionnaire "Psychological Safety of the Educational Environment" by I.A. Baeva produced various results. Because of the peculiarities of the questionnaire composition, we provide the results from each component.

The first portion of the questionnaire reveals pupils' attitudes toward the school educational environment. The distribution of pupils according to three types of attitude (positive, neutral and negative) toward the school educational environment is presented in Figure 1.

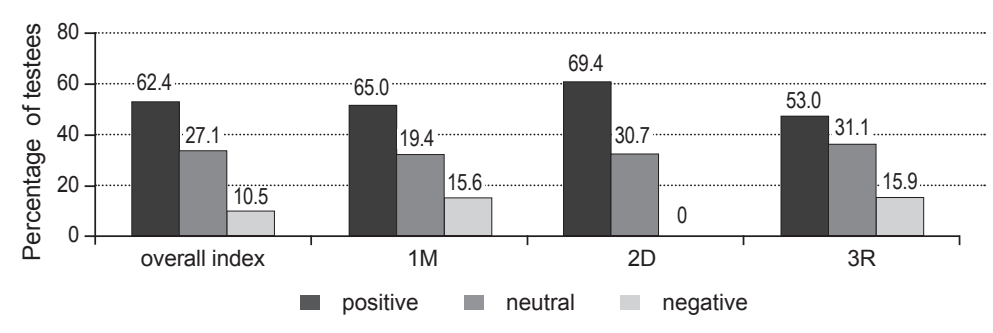

Figure 1. Distribution of the student participants according to the index of attitude toward the school educational environment

The best situation is observed in subsample " $2 \mathrm{D}$ ". The index "negative attitude" was not identified in this group of pupils. A positive attitude toward the educational environment was reported by $69.3 \%$ of the pupils, and a neutral attitude was reported by $30.7 \%$ of the pupils. The pupils in the subsample " $1 \mathrm{M}$ " demonstrated quite a good attitude toward their educational environment. The number of pupils with the index "positive attitude" was $65.0 \%$, which is nearly twice as many as the number of respondents with neutral (19.4\%) and negative attitudes (15.6\%). In the third subsample, "3R", $15.9 \%$ of the pupils clearly stated their negative attitude toward their school. The number of students in the study with the index "positive attitude" was $53.0 \%$, and the neutral attitude was conveyed by $31.1 \%$ of the respondents. In most cases (63.6\%), the pupils assessed the mood of the school positively, and $79.5 \%$ of the pupils scored their school by the criteria "I don't like - I like" from 7 to 9 points on a scale of $1-9$. This attitude may be a result of this being 
the only available school for the pupils in the village and neighboring settlements; therefore, the children do not see the possibility of choosing another school.

When defining more significant characteristics of the educational environment and the level of pupils' satisfaction with these characteristics, we focused on the following indices of the second portion of the questionnaire:

- relationships with teachers

- relationships with pupils

- the ability to express one's own point of view

- respect for himself/herself

- preservation of personal dignity

- being able to ask for assistance

- possibility of taking initiative, zeal

- considering personal problems and difficulties

Significant characteristics of the educational environment were evaluated according to a five-point scoring system. Correlation of the data regarding characteristics of the educational environment provides insight into such significant characteristics as the possibility of asking for assistance, preservation of personal dignity, relationships with other students, and respect for oneself.

Significant characteristics for the pupils in subsample " $1 \mathrm{M}$ " are being able to ask for assistance (4.1 points), relationships with other students (3.9 points), preservation of personal dignity (3.9 points), respect for himself/herself (3.5 points), and considering personal problems and difficulties (3.4 points). The students in subsample "2D" attach special significance to the preservation of personal dignity (4.1 points), the being able to ask for assistance (4.1 points), respect for himself/ herself ( 3.6 points), the possibility of taking initiative, and zeal (3.5 points). Significant characteristics for subsample " $3 \mathrm{R}$ " are relationships with other students (4.3 points), being able to ask for assistance ( 4.2 points), the preservation of personal dignity (4.1 points), relationships with teachers, and respect for himself/herself (3.5 points).

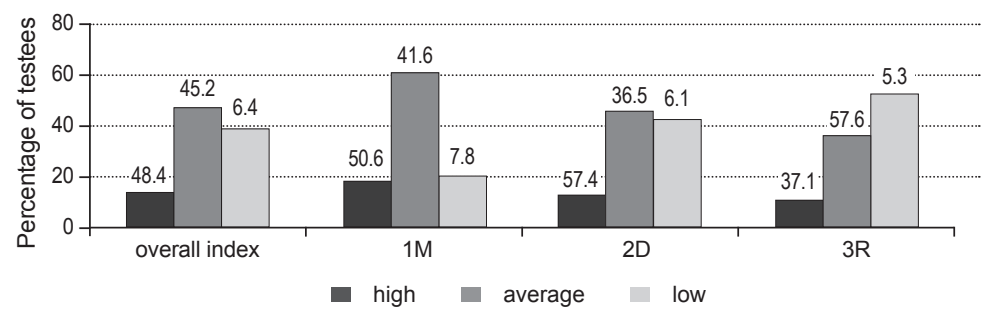

Figure 2. Distribution of the pupils under study according to their levels of satisfaction with all characteristics of the school educational environment

Analyzing the distribution of the pupils in this study by levels of satisfaction with the educational environment (Figure 2), we observe a high level of satisfaction in subsample "2D" (57.4\%), which exceeds the overall index (48.4\%) whereas only $37.1 \%$ of the pupils expressed a high level of satisfaction in subsample " $3 R$ ". The 
reason for the decline in their level of satisfaction with the educational environment may be pupils' unmet needs for emotionally positive relationships with peers, feeling unable to ask for assistance and believing that their personal dignity has been violated.

The third portion of the questionnaire presents particular and overall indices of the level of protection from psychological abuse in the educational environment. I.A. Baeva suggested the following directions for this purpose:

- protection from humiliation/insults

- protection from threats

- protection from compulsion

- protection from social isolation

- protection from unkind attitudes

Evaluating the level of protection from psychological abuse was conducted according to a five-point system. Correlating estimates of levels of protection from psychological abuse indicated that all of the students in the study were primarily protected in the index of protection from social isolation (3.5 and 3.6 points). In addition, students in subsample "2D" reported a high level of protection from threats ( 3.4 points), and students in subsample " $3 \mathrm{R}$ " reported a high level of protection from humiliation/insults (3.5 points).

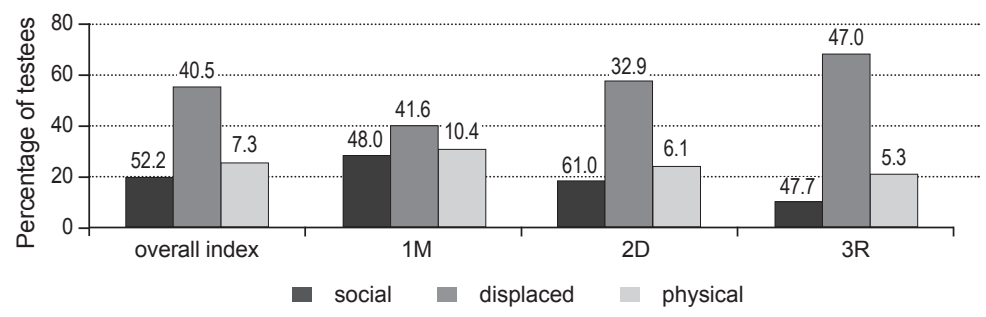

Figure 3. Distribution of the pupils in the study by levels of protection from psychological abuse in cooperation

Analyzing the distribution of the students according to levels of protection (Figure 3) indicates that the students in subsample "1M" have deeper feelings of vulnerability in the educational environment. Experiencing high levels of psychological protection is typical only in $48.0 \%$ of the pupils, which is slightly lower than the overall index of the same level (52.2\%). A greater number of the students $(10.4 \%)$ in this subsample were psychologically abused.

Examining class environment attractiveness according to A.A. Rean's methods enhances the conception of a pupil's psychological safety in the educational environment. Classifying students according to grade point average was key to interpreting class team attractiveness. The highest degree of class team attractiveness was in subsample " $2 \mathrm{D}$ " (67.1\%), the only group with no negative assessments.

In subsamples " $1 \mathrm{M}$ " and " $3 \mathrm{R}$," $52.0 \%$ and $47.7 \%$ of students described the atmosphere of their classroom as comfortable and favorable, respectively. An approximately equal number of pupils (15.6\% and $15.9 \%)$ gave a neutral assessment 
to their class atmosphere in the same groups. A neutral attitude toward the class atmosphere is evidence of the presence of certain uncomfortable relationships that influence a pupil's perception of her/his own position in the class.

To identify more possible uncomfortable experiences in the group of coevals and to present a more comprehensive view of psychological protection, we used the multifactorial scale of coevals' victimization by I.A. Furmanov. This method measures levels of aggression and suggests acquiring information regarding the frequency of direct forms of physical, verbal and social aggression.

Distribution of the students according to the index of total victimization (Picture 4) was performed on three levels (low, moderate and high). The overall index indicates that most pupils (80.1\%) are not victims of aggressive actions from their classmates or coevals. The subsample " $3 \mathrm{R}$ " appears to be in a better position than the general population. In this group, the level of total victimization was lowest $(89.4 \%)$. There were no high levels scored in this subsample.

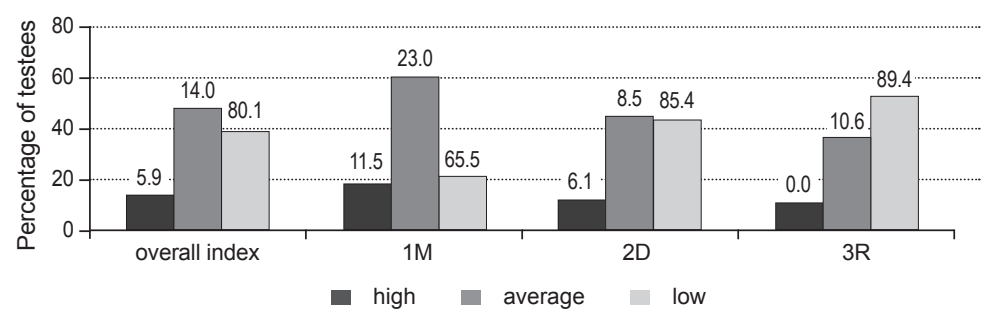

Figure 4. Distribution of the pupils in the sample according to levels of total victimization

In subsample " $2 \mathrm{D}$," some pupils assessed their total victimization at high and moderate levels, $6.1 \%$ and $8.5 \%$, respectively, compared with the majority of the students $(85.4 \%)$, who rated the level of their total victimization at school as low. These indices do not define an educational environment of complete victimization; the results are evidence of certain manifestations of various types of victimization.

The students in subsample " $1 \mathrm{M}$ " were exposed to aggression from their coevals and classmates to a greater extent. The number of students who defined the level of victimization as low was $65.5 \%$ whereas $44.5 \%$ of the students defined their level of victimization as moderate or high.

An analysis of the results identifies the dominant type of victimization in the subsamples. Displaced aggression is the dominant type in all three subsamples (as well as according to the overall index - 55.1\%). Of the pupils in the study, $68.0 \%$ were exposed to displaced aggression in group " $3 \mathrm{R}$ ", and $21.4 \%$ of the respondents in this group were exposed to physical aggression. Of the pupils, $10.6 \%$ were victims of social aggression in subsample " $3 \mathrm{R}$ ". Of the pupils, $57.3 \%$ were exposed to displaced aggression from their classmates in group " $2 \mathrm{D}$ ”; $24.4 \%$ of the respondents were exposed to physical aggression, and $18.3 \%$ of the students were exposed to social aggression in group " $2 \mathrm{P}$ ". Of the pupils, $40.2 \%$ experienced displaced aggression in subsample " $1 \mathrm{M}$," and $31.2 \%$ of the respondents in this group were exposed to physical victimization. In group " $1 \mathrm{M}$," $28.6 \%$ of the pupils experienced social aggression and manipulation. 
Insignificant differences in the dominant types of victimization in the educational environment of these schools may be results of both external and internal factors. The most significant factors are groups of pupils, ethnic and cultural composition, peculiarities of the educational system, relationships between "a teacher - a pupil", the individual and personal characteristics of pupils, and teachers.

We identified confidence as a personality trait based on positive self-esteem and positive experiences with solving social tasks as criteria of a pupil's psychological safety. However, a pupil's increased anxiety can lead to a decline in self-esteem and painful experiences.

To study the level and nature of school anxiety, we used Fillips' methods to diagnose school anxiety level, having defined common school anxiety, experiences of social stress, and fear of self-expression as the most significant factors that characterize a pupil's psychological safety. The intensity of these factors in the pupils is shown in Table 2.

Table 2. Indices of the factors of school anxiety (in points)

\begin{tabular}{cccc}
\hline Pupils under study & Common anxiety & $\begin{array}{c}\text { Experience of } \\
\text { social stress }\end{array}$ & $\begin{array}{c}\text { Fear of self- } \\
\text { expression }\end{array}$ \\
\hline 1M & $\mathbf{1 5 . 0}$ & $\mathbf{6 . 0}$ & $\mathbf{4 . 0}$ \\
2D & 10.0 & 5.0 & 2.0 \\
3R & 8.0 & 5.0 & 3.0 \\
\hline
\end{tabular}

The analysis of the results according to certain factors of school anxiety shows the highest level of all indices in subsample " $1 \mathrm{M}$ ". In the other two groups, indices of anxiety were at moderate and low levels. A more detailed examination of the factor of common anxiety indicated the levels of its occurrence.

An analysis of the distribution results of the pupils by levels indicates that moderate (normal) levels of common school anxiety are typical for the sample group as a whole. Higher levels of school anxiety in subsample " $1 \mathrm{M}$ " (18.7\% of the pupils) are conspicuous against the general background. Such pupils can display emotional instability and often experience worry and uneasiness. The pupils in subsamples " $2 \mathrm{D}$ " and " $3 \mathrm{R}$ " worried less; the level of anxiety was normal in both groups.

Table 3. Distribution of the pupils by types of ethnic identity with the indices of the corresponding type intensity

\begin{tabular}{cccccc}
\hline \multicolumn{5}{c}{ Types of ethnic identity } \\
En & Ei & PEi (Norm) & Ee & Eis & Ef \\
\hline \multicolumn{7}{c}{ Indices of intensity of each type of ethnic identity in points } \\
13.6 & 14.0 & 14.6 & 11.0 & 0.0 & 0.0 \\
& Distribution of the pupils according to the types of ethnic identity \\
17.7 & 11.8 & 58.7 & 11.8 & 0.0 & 0.0 \\
\hline
\end{tabular}

Note. The following abbreviations are used: En - ethno-nihilism, Ei - ethnic indifference, PEi positive ethnic identity (Norm), Ee - ethno-egoism, Eis - ethno-isolationism, Ef - ethno-fanaticism. 
Another important factor that determines the level of school anxiety in the multicultural educational environment is social stress, which may be a result of the transformation of ethnic identity.

To identify the level of ethnic intolerance, we used the methods of evaluation of ethnic identity types by G.U. Soldatova and S.V. Ryzhova. We noted two of six scales of the questionnaire, ethno-egoism and ethno-isolationism, that correspond to different types of ethnic identity. The results for the entire sample of students $(n=127)$ according to the six scales are presented in Table 3.

The majority of students (58.7\%) share an ethnic identity that corresponds to the norm, i.e., a positive ethnic identity. Ethno-nihilism was identified in $17.7 \%$ of the pupils; for this category of pupils, ethnic background is not of critical importance. Ethno-egoism was displayed by $11.8 \%$ of the pupils, for example, in tense or irritating situations with pupils of other nationalities. The same number of students (11.8\%) displayed ethnic indifference, i.e., uncertainty regarding their ethnic background. The pupils who demonstrated this type of ethnic identity were inclined to show more tolerance toward students of different cultures.

Types of ethnic identity such as ethno-isolationism and ethno-fanaticism were not displayed by the pupils, which indicates an absence of a belief in the supremacy of their nation in the group and an absence of xenophobia.

Consequently, the level of "negativism" toward their nation is low in the group as a whole, and there is no vivid separation of their ethnic group compared with other groups.

To determine the results of evaluating psychological safety, we introduced the integrated index of psychological safety condition, which was calculated by summarizing all of the data from the chosen criteria: satisfaction, protection, and selfconfidence. The empirical data revealed the current condition of psychological safety of the entire student sample. Then, all of the criteria of psychological safety were subjected to correlation analysis (Pearson $r$ ), which identified tightness links among the criteria (Table 4).

Table 4. Correlation matrix of interrelations of the criteria of pupils' psychological safety in the multicultural educational environment

\begin{tabular}{ccccc}
\hline $\begin{array}{c}\text { Criteria } \\
\text { of psychological safety }\end{array}$ & S & P & Sc & Ii \\
\hline S & $\times$ & 0.58 & 0.45 & 0.79 \\
P & & $\times$ & 0.55 & 0.82 \\
Sc & & & $\times$ & 0.61 \\
\hline
\end{tabular}

Note. The following abbreviations are used in the table: $\mathrm{S}$ - satisfaction; $\mathrm{P}-$ protection; $\mathrm{Sc}-$ selfconfidence; Ii- integrated index.

The analysis of the statistical processing of the results of pair correlation indicated the following:

1) There is a direct correlation among all of the criteria of psychological safety, including the integrated index. 
2) There is a positive relation between criteria $\mathbf{S}$ and $\mathbf{P}$. The correlation coefficient in this case was $r=0.58$ (level of significance $p=0.05$ ), which indicates a moderate correlation.

3) There is a positive relation between criteria $\mathbf{P}$ and $\mathbf{S c}$. The correlation coefficient in this case was $r=0.55$ (level of significance $p=0.05$ ), which indicates a moderate correlation.

4) There is a positive relation between criteria Ii and Sc. The correlation coefficient in this case was $r=0.61$ ( level of significance $p=0.05$ ), which indicates a moderate correlation.

5) There is a positive relation between the criteria Ii and $\mathbf{S}$. The correlation coefficient in this case was $r=0.79$ ( level of significance $p=0.05$ ), which indicates a strong correlation.

6) There is a positive relation between criteria Ii and $\mathbf{P}$. The correlation coefficient in this case was $r=0.82$ ( level of significance $p=0.05$ ), which indicates a strong correlation.

Notably, the presence of a correlation does not establish the sequence of cause and effect but only indicates that two variables are interrelated to a greater extent than one would expect by random coincidence.

The research findings on students' psychological safety in multicultural educational milieu led to the following conclusions:

- Students' psychological safety level is defined by the intensity of the criteria in the following order of significance: 1) protection, 2) satisfaction, and 3) self-confidence. Being on good terms with other members of the educational environment, having parents' and teachers' support, having classmates' sympathy and experiencing a low level of aggression from classmates and teachers positively affect protection. The high comfort level of the class's psychological atmosphere, mutual understanding and contact with teachers, confidence in teachers, mutual aid and support between counterparts and an absence or low level of aggression in classmates and other students in the school favorably affect pupils' self-satisfaction as a subject of activity and social relations. The high level of pupils' relying on teachers in difficult situations, children's mutual aid and support, low aggression levels of classmates and older students and a democratic style of teaching influence self-confidence.

- According to students, the essential characteristics of safety in an educational environment, regardless of school category and type, are being able to ask for help, protection of personal dignity, interaction with other students, and self-respect.

- The highest level of protection from mental violence in interactions and satisfaction with the educational environment indicative of pupils' psychological safety is in subsample " $2 \mathrm{D}$ " (district school). This is a "small town" or district center school. The number of schools in towns at the district level is less than in regional centers; thus, the students attending a school generally live in the same community and are well-acquainted with one another. 


\section{Conclusion}

This study examines pupils' psychological safety in a multicultural educational environment. Because of our modern multicultural society, the necessity to preserve students' psychological safety is extremely important. The educational environment is the place in which key activities occur and a pupil's personality and primary characteristics develop. Thus, the quality of the educational environment is the primary factor in a pupil's psychological safety. The quality of the educational environment is defined by its ability to meet the basic needs of children. There is a need for safety, recognition, acceptance, esteem, social approval, love, for maintaining and increasing self-evaluation, for satisfaction and the development of cognitive needs and the need for labor and significant activity. Satisfying these needs enables a child to preserve his physical and mental health.

Creating an optimal microenvironment and a favorable moral and psychological climate in the classroom contributes significantly to students' psychological safety in a multicultural educational milieu. The need to understand and accept another culture with its unusual traditions, behavior and communication peculiarities defines the direction for future research on teachers' polyethnic competence levels.

\section{Acknowledgements}

The article was supported by the Russian Foundation for Humanities, grant No. 15-16-71005 a/C.

\section{References}

Baeva, I. A., Volkova, E. N., \& Laktionova, E. B. (2009). Psihologicheskaja bezopasnost obrazovatelnoj sredy [Psychological safety of the educational environment]. Moscow: Ekon-Inform.

Banks, J. (1996). Multicultural education, transformative knowledge and action. New York: Teachers College Press.

Bessarabova, I. S. (2007). Polikulturnost obrazovanija kak filosofskaja i psihologo-pedagogicheskaja problema [Multicultural education as a philosophical, psychological and pedagogical problem]. Sovremennye naukoemkie tehnologii [Modern Scientific Technologies], 3, 63-67.

Bluestein, J. (2001). Creating emotionally safe schools: a guide for educators and parents. Deerfield Beach, FL: HCI Pub.

Brand, S., Felner, R., Shim, M., Seksinger, A., \& Dumas, T. (2003). Middle school improvement and reform: Development and validation of a school's assessment of climate, cultural pluralism, and school safety. Journal of Educational Psychology, 95(3), 570-588. doi: $10.1037 / 0022-0663.95 .3 .570$

Bronfenbrenner, U. (1979). The ecology of human development: Experiments by nature and design. Cambridge, MA: Harvard University Press.

Fend, H. (1977). Schulklima: soziale Einflussprozesse in der Schule. Soziologie der Schule III. [School climate: Social influence processes at school. Sociology for school III]. Weinheim/ Basel: Beltz Verlag.

Gorokhov, B. M. (2009). Polikulturnoe obrazovanie uchashhihsja $v$ dejatel'nosti otechestvennyh zagranshkol [Multicultural education of students in activities of national schools abroad] 
(Unpublished doctoral dissertation). Tula, Russia: Tula State Lev Tolstoy Pedagogical University.

Grant, C. (2008). The evolution of multicultural education in the United States: A Journey for human rights \& social justice. Cooperative learning in multicultural societies: Critical reflections. Turin: Papers from the IAIE-IASCE Conference.

Grant, C.A., \& Chapman, T.K. (Eds.). (2008). History of multicultural education. Vol. 2. New York: Routledge.

Kolobova, L. V. (2005). Multidimensional nature of multicultural education. Vestnik of OSU, 10. Vol. 1. Humanities, 105-114.

Kulikova, T.I., \& Osipova N.V. (2015). Ocenka mezhjetnicheskih otnoshenij podrostkov kak prediktor psihologicheskoj bezopasnosti polikulturnoj obrazovatelnoj sredy [Evaluation of inter-ethnic relations as a predictor of adolescent psychological safety of multicultural educational environment]. Mir nauchnykh otkrytiy [World of Scientific Discoveries], 5.2(65), $828-842$.

Leontiev, A. N. (1998). Selected psychological works. Moscow: Pedagogika. (Original work published 1973)

Moos, R. H. (1979). Evaluating educational environments. Procedures, measures, findings and policy implications. San Francisco: Jossey-Bass Publischers.

Nieto, S. (2004). Affirming diversity: the sociopolitical context of multicultural education. Boston: Pearson Allyn \& Bacon.

Polivanova, N. I. (2000). Obrazovatelnaja sreda uroka v shkolah raznyh tipov [Educational environment of a lesson in different types of schools]. Psihologicheskaja nauka i obrazovanie [Psychological science and education], 3, 72-80.

Rubinstein, S. L. (2003). Bytie i soznanie. Chelovek $i$ mir [Being and consciousness. The human and the world]. St. Petersburg: Piter. (Original work published 1957)

Shevchuk, S. V. (2006). Razvitie idej pravoslavnoj pedagogiki v nasledii K.D. Ushinskogo [Development of ideas in heritage of the Orthodox pedagogy by K.D. Ushinsky] (Unpublished doctoral dissertation). Yaroslavl, Russia: Yaroslavl State Pedagogical University named after K.D. Ushinsky.

Volova, L. A. (2008). Dialektika dialoga jetnokultur [Dialectics of ethnocultural dialogue]. Nauchnye problemy gumanitarnyh issledovanij [Scientific Issues in Humanities Research], 12, 231-233.

Vygotsky, L. S. (1984). Collected works in six volumes. V. 4. Moscow: Pedagogika.

Yasvin, V. A. (2001). Obrazovatelnaja sreda. Ot modelirovanija k proektirovaniju [Educational environment: from modeling to designing]. Moscow: Smysl.

Original manuscript received September 30, 2015

Revised manuscript accepted April 05, 2016

First published online September 30, 2016 